\title{
1 Predation threat alters composition and functioning of bromeliad ecosystems
}

2 Edd Hammill $^{1,2}$, Trisha B. Atwood ${ }^{3,4}$ and Diane S. Srivastava ${ }^{1}$

$3{ }^{1}$ Department of Zoology \& Biodiversity Research Centre, University of British Columbia,

46270 University Blvd., Vancouver, BC, Canada, V6T 1Z4,

$5{ }^{2}$ School of the Environment, University of Technology, Sydney, Ultimo, NSW, Australia,

$6 \quad 2007$

$7 \quad{ }^{3}$ Department of Forest and Conservation Sciences, University of British Columbia,

8 Vancouver, BC, V6T 1Z4, Canada

$9 \quad{ }^{4}$ Global Change Institute Building (\#20), Staff House Rd, University of Queensland 4072

11 Running title: Risk of predation modifies ecosystems

12

13 Correspondence e-mail to Edd Hammill - edd_hammill@hotmail.com

14 Abstract - 248

15 Main body text -3782

16 Tables - 1

17 Figures -4

18 References -49

19 Appendices - 1, (319 words)

20 Keywords (alphabetical order)

21 bromeliad communities, $\mathrm{CO}_{2}$ dynamics, community ecology, ecosystem function, Odonata,

22 predator-prey, mosquito, non-consumptive effects, trophic cascade

23

24 Author contributions. E.H., T.B.A and D.S.S. designed the study. The experiment was

25 conducted in the field by E.H. and T.B.A. All authors contributed to the writing of the MS. 


\section{Abstract}

2 Predators can have dramatic effects on food web structure and ecosystem processes.

3 However, the total effect of predators will be a combination of prey removal due to

4 consumption and non-consumptive effects (NCEs) mediated through changes to prey

5 behavioural, morphological, or life history traits induced to reduce predation risk. In this

6 study, we examined how consumptive and non-consumptive effects alter community

7 composition and ecosystem function using the aquatic ecosystem housed within tropical

8 bromeliads. We allowed the recolonization of emptied bromeliads containing either no

9 predators, caged predators (NCEs only), or uncaged predators (NCEs and consumptive

10 effects) and recorded densities of all macro-invertebrates, microbial densities and in situ $\mathrm{CO}_{2}$

11 concentrations after 30 days. We found that predators altered community composition and

$12 \mathrm{CO}_{2}$ concentrations largely through NCEs. The magnitude of the effects of NCEs was

13 substantial, contributing $>50 \%$ of the total effects of predators on macro-invertebrate

14 communities. The non-consumptive effects of predators were also strong enough to generate

15 a trophic cascade, which significantly increased micro-organisms and ecosystem respiration,

16 which led to increased in situ $\mathrm{CO}_{2}$ concentrations. The most likely mechanism behind the

17 NCEs on macro-invertebrate density was detection of predator cues by ovipositing adult

18 females, who actively choose to avoid bromeliads containing predators. Through this

19 mechanism, predator NCEs modified community colonization, the structure of food webs,

20 populations of lower trophic levels, and ecosystem processes performed by the community.

21 We therefore propose that quantification of the relative strength of predator NCEs in natural ecosystems is critical for predicting the consequences of predator loss from the world's ecosystems. 


\section{Introduction}

2 The total effect of predators on prey is a combination of direct consumption, and predator

3 non-consumptive effects (NCEs). Predator NCEs may take several forms, such as changes in

4 prey behavioural, morphological or life history traits (Tollrian and Harvell, 1999; Peacor and

5 Werner, 2001). Predator NCEs are particularly common and strong in ecosystems with sit-

6 and-wait predators (Preisser et al., 2007), which provide a point source indicator of the risk of

7 attack. The magnitude of the effect of predator NCEs on prey life history and population

8 dynamics can be large, and has been shown to be greater than the effects of direct

9 consumption (Trussell et al., 2006b).

10 Previous studies have demonstrated that predators can generate trophic cascades

11 through NCEs alone (Schmitz et al., 1997; Forbes and Hammill, 2013), and affect ecosystem processes (Strickland et al., 2013). However, past research into NCEs has focused on simple, two or three trophic level food chains (Trussell et al., 2006a), often with each trophic level represented by a single species (although see Peacor et al. (2012)), and with species densities determined by the investigators. While providing valuable insights, the results of these previous experiments may not scale up to the ecosystem level as the effects of predators may be enhanced by both artificial manipulation of densities, and the reduction of complex food webs to linear food chains (Carpenter, 1996). This potential for exaggeration in simple, linear food chains necessitates conducting experiments using complex, natural, replicated ecosystems to determine the realized magnitude of predator NCEs.

Predator NCEs may affect community dynamics through a variety of individual-level mechanisms. Prey species that cross ecosystem boundaries through ontogeny, such as insects and amphibians that have terrestrial adult stages but oviposit in aquatic ecosystems, may avoid locations within a landscape that have a high predation risk for their larvae (Berendonk and Bonsall, 2002; Resetarits and Binckley, 2009; Vonesh and Blaustein, 2010). These 
1 changes in adult oviposition behaviour alter colonization rates, changing eventual community

2 composition (Kraus and Vonesh, 2010). Aquatic predators can also have NCEs on larvae,

3 such as increasing larval development rates to reduce exposure to predation, and altering gut

4 morphology to reduce detection by predators (Hammill and Beckerman, 2010). Additionally,

5 the threat of predation can reduce foraging rates of competitively dominant prey, influencing

6 community dynamics (Werner and Anholt, 1996). These predator-mediated pre- and post-

7 colonization processes together determine community structure (Vonesh et al., 2009). Environmental changes that affect species composition can alter rates of ecosystem

9 processes, and ultimately ecosystem function (Schulze and Mooney, 1994; Cadotte et al., 10 2011; Hooper et al., 2012). The relationship between community composition and ecosystem 11 functioning implies that NCE-mediated changes to communities likely play a central role in 12 how ecosystems function. Previous studies have demonstrated that predators are able to alter 13 the carbon balance of ecosystems, influencing their capacity to sequester $\mathrm{CO}_{2}(\mathrm{Schindler}$ et 14 al., 1997) However, accurately predicting the effects of changes to predator abundance on 15 the carbon balance of an ecosystem is hindered by our limited understanding of how NCEs 16 influence community composition. The link between predator NCEs and carbon storage may 17 be particularly important in freshwater ecosystems, which have a high prevalence of NCEs 18 and emit relatively high levels of $\mathrm{CO}_{2}$ [up to $1.65 \mathrm{Pg} \mathrm{C} \mathrm{yr}^{-1}$; (Cole et al., 2007)]. Bromeliads are ideal ecosystems to study community and ecosystem ecology. Their 20 small size and abundance makes them ease to manipulate, but their complex foodwebs and 21 structure make them as biologically realistic as other natural systems (Srivastava et al., 2004). 22 Bromeliad leaves are arranged in a rosette structure, and within the wells created by the leaf 23 axils exists an aquatic, detrital-based ecosystem (Figure 1a). As a result of their heterotrophic 24 nature, bromeliads are large natural sources of $\mathrm{CO}_{2}$ and methane (Martinson et al., 2010; 25 Atwood et al., 2013; Atwood et al., 2014), and are one of the major contributors to high 
1 levels of greenhouse gas observed over neotropical forests (Martinson et al., 2010; Goffredi

2 et al., 2011). Bromeliad communities experience periodic droughts that can lead to the loss

3 of many members of the community, and are therefore in a seasonal cycle of drought and re-

4 colonization (Srivastava et al., 2008). Following the onset of rain, bromeliad ecosystems are

5 colonized by macro-invertebrate insect larvae, including predatory Odonata, mosquitoes

6 (Culicidae - filter feeders and browsers), as well as detritivorous Chironomidae, Tipulidae

7 and Scirtidae. Throughout the rainy season, adult insects continuously add larvae to the

8 community though oviposition, and individuals are lost from the bromeliad as they emerge as

9 adults or die. Bromeliad ecosystems also contain a broad microbial community, including

10 ciliates (subphylum Ciliphora), flagellates (subphylum Mastigophora), and rotifers. This

11 microbial community consumes bacteria, fungi, and detritus. Thus, the community within the bromeliad contains at least two different food chain components, the mosquito-microbial food web and the macro-invertebrate detritivore food web, with larvae of the damselfly Mecistogaster modesta (Selys, 1860) acting as the top predator in both (Figure 1b).

We quantified predator NCEs on community composition and community respiration using the natural ecosystems contained in the water-filled leaf axils of Guzmania spp. bromeliads. As $M$. modesta are generalist predators able to consume a wide variety of macroinvertebrates, all macro-invertebrates are expected to be at risk of consumption, and experience some selection pressure to avoid bromeliads containing M. modesta.

20 Furthermore, biogeochemical and nutrient cycling in bromeliads is largely controlled by top21 down processes (Ngai and Srivastava, 2006; Atwood et al., 2014), and the presence of $M$.

22 modesta has large influences on the magnitude of $\mathrm{CO}_{2}$ emissions from bromeliads (Atwood et al., 2013; Atwood et al., 2014). We therefore made three hypotheses: 1 - the presence of

24 predators would lead to lower densities of all macro-invertebrate species. 2 - The reduction in macro-invertebrates would create a trophic cascade, releasing the microbial community from 
1 the pressures of macro-invertebrate predation (especially from mosquitoes), increasing

2 densities of protists and rotifers. 3 - Predator NCEs on the macro-invertebrate and microbial

3 communities significantly affect rates of community respiration [as approximated by $\mathrm{CO}_{2}$

4 concentrations within the water column (Del Giorgio et al., 1999)], although the direction of

5 this effect cannot be predicted a priori as a result of the highly complex nature of the

6 bromeliad food web (especially among omnivorous protists and mosquitos; Figure 1b)

7

\section{Materials and Methods}

9 We collected 30 bromeliads from the genus Guzmania from a tropical mid-elevation

10 rainforest ( 700 m above sea level) within $5 \mathrm{~km}$ of Estación Biológica Pitilla, Área de

11 Conservación Guanacaste, Costa Rica. Prior to being used in the experiment, all bromeliads were thoroughly washed and immersed in water in an inverted position for $24 \mathrm{hrs}$, then left to dry for 7 days. This method eliminated most if not all invertebrates and residual chemical cues from predators prior to use. Our study was conducted during the rainy season (October and November), when oviposition by mosquitoes, Chironomidae, Tipulidae and Scirtidae is highest and M. modesta are in mid-instars (Srivastava, 2006). Additionally, M. modesta rarely oviposit during the rainy season, which helped ensure that predator free treatments remained free of $M$. modesta throughout the study (Srivastava, 2006). At the start of the experiment, plants were moved to a $30 \mathrm{~m}$ x $30 \mathrm{~m}$ patch of secondary forest, and suspended

20 from trees that had a diameter at breast height greater than $10 \mathrm{~cm}$. The wells of the plants were filled using commercially available mineral water. Leaf litter from Conostegia xalapensis Bonpl., a common pioneer species, was distributed throughout the plant at a density of $200 \mathrm{mg}$ (dry weight) per $100 \mathrm{ml}$ (total plant volume) to act as food for the

24 community. 
Prior to the start of the experiment, we recorded the maximum volume of water each

2 plant could hold, and randomly assigned them to three experimental treatments: no predators,

3 caged predators (predator NCEs only) and uncaged predators (NCE's and consumptive

4 effects of predators, hereafter referred to as total predator effects). Each treatment was

5 represented by 10 replicates, and plants did not significantly differ in size between treatments

6 (volume range $500-1500 \mathrm{ml}$, mean $1013.5 \mathrm{ml}, \mathrm{F}_{(1,28)}=2.17, \mathrm{p}=0.15$ ). The strength of

7 predator NCEs can be related to predator biomass, with larger predators generating stronger

8 effects (Hill and Weissburg, 2013). To minimize the confounding effect of predator size, all

9 predators used in the experiment were mid-instar M. modesta larvae with body lengths of 12

$10-15 \mathrm{~mm}$. A single M. modesta larva was added either inside the cage for caged (NCE only)

11 replicates or outside the cage for uncaged (total predator effect) replicates. Using a single predator per plant represents natural $M$. modesta densities for the size of bromeliads used in our study (Srivastava et al., 2005; Hammill et al., 2015). Predator cages consisted of $50 \mathrm{ml}$ clear centrifuge tubes. Two $15 \mathrm{~mm}$ diameter holes were drilled in the sides of the tubes and covered with $80 \mu \mathrm{m}$ mesh. These mesh-covered holes allowed water inside and outside the cages to mix, facilitating diffusion of predator chemical cues. We added empty cages to no predator and uncaged predator treatments to ensure differences between treatments were not due to cages per se. All cages were placed inside a leaf well in the second row of leaves from the centre of the plant. Placing the cage relatively close to the centre ensured that chemical cues from a caged predator could diffuse down through the rest of the plant, as water cascades down through the bromeliad during rain showers. Caged predators were fed a single mosquito and chironomid larvae every other day, whereas uncaged predators consumed insects within the bromeliads. We mimicked the feeding procedure in the uncaged predator and no predator treatments to ensure adequate control, in case adult mosquitoes were attracted to plants by our presence. 
After the 30 day experimental colonization period, we compared differences in macro-invertebrate community composition, microbial density, and in situ $\mathrm{CO}_{2}$ concentration.

3 A 30 day study period was used as it allowed for multiple colonization events, while

4 minimizing loss from emergence. Chironomidae, Tipulidae and Scirtidae colonizing the

5 bromeliads have larval stages that are typically greater than one month in duration

6 (Srivastava, 2006). Although 30 days may have exceeded the larval period of some mosquito

7 species in this study, oviposition by adult mosquitos is ongoing throughout the rainy season.

At the end of the experiment, we randomly selected a leaf well that had not contained

9 the cage, and collected a $1 \mathrm{ml}$ water sample, which was preserved with Lugols media and

10 later used to calculate protist and rotifer densities. In a different well, $6 \mathrm{ml}$ of water was

11 extracted using a $50 \mathrm{ml}$ Pressure-Lok® syringe (VICI Precision Sampling Corp., Baton

12 Rouge, LA), injected in a gas tight vacutainer (Labco Limited High, Wycombe, UK.), chilled and transported within $72 \mathrm{~h}$ to the Department of Civil Engineering, Environmental

14 Laboratory at the University of British Columbia for analysis of dissolved $\mathrm{CO}_{2}$ gas concentrations. Two $\mathrm{CO}_{2}$ samples were compromised during transit, and thus not included in the analysis. Collections and calculations of $\mathrm{CO}_{2}$ concentrations from sample water followed established procedures (Hope et al., 1995)

Following $\mathrm{CO}_{2}$ collections, we removed all water, insects and detritus from the plant.

Insect larvae were sorted and preserved in ethanol within six hours. We identified mosquito

20 larvae to species, while other insects (largely Chironomidae, Tipulidae and Scirtidae) were

21 sorted to family level. For each plant, we calculated macro-invertebrate density (the total

22 number of individuals of each species divided by plant volume) in order to directly compare organisms from plants of different sizes. Data are available on the Knowledge Network for

24 Biocomplexity (http://knb.ecoinformatics.org/knb/metacat/knb.302.1/knb).To estimate 
1 the original Lugols-preserved sample. Five micro-organism samples were compromised

2 during transit to the University of British Columbia, and removed from the analysis.

As our macro-invertebrate community composition data required the analysis of

4 multiple response variables (i.e. the density of each species), and a single explanatory

5 variable (predator treatment), we opted to use a multivariate approach. The "adonis" function

6 from the package "vegan" (Oksanen et al., 2012), built using the R statistical language (R

7 Development Core Team, 2013), can be used to carry out permutational analysis of variance

8 (PERMANOVA) using distance matrices, and is a generally robust method to investigate

9 differences in multivariate data. We initially ran a PERMANOVA comparing differences in

10 macro-invertebrate community structure among the three experimental treatments (no

11 predator, caged predator, uncaged predator, $\mathrm{n}=10$ for each treatment). To establish which treatments differed from each other, we carried out post-hoc pair-wise comparisons of each treatment pair, and applied a Bonferroni correction to avoid inflating the chance of finding significant results (Holm, 1979). Differences in macro-invertebrate community structure between the experimental treatments were visualized using multidimensional scaling plots

16 (Borg and Groenen, 2005). Multidimensional scaling uses ordination techniques to display the information within a distance matrix. Each replicate is assigned a co-ordinate in each of n-dimensions, by setting $\mathrm{n}=2$, data can be plotted in 2-dimensional space. Within this space, replicates that are close together are similar to each other, while replicates that are far apart are different (Garpe et al., 2006). While PERMANOVA is useful to elucidate differences between multiple response variables, it does not describe how communities differ. We therefore subsequently used ANOVAs and post-hoc Tukey's tests to look at the differences in populations of different community members, and to investigate differences in community respiration (dissolved $\mathrm{CO}_{2}$ concentrations in the water). In order to account for non-normality of the data, mosquito, macro-invertebrate detritivore, and micro-organismal densities were 
$1 \log$ transformed prior to analysis. In order to avoid inflating the chance of finding significant

2 differences due to running multiple tests, we applied a Holm-Bonferroni correction to the P-

3 values generated from the ANOVAs, and report the corrected P-values in the results.

After we used formal statistical analysis to demonstrate the differences between

5

6 experimental treatments in consumer densities and dissolved $\mathrm{CO}_{2}$ concentrations, we used randomized bootstrap methods to quantify the proportion of total predator effects accounted for by NCEs. We randomly sampled, with replacement, 10 replicates within each treatment and calculated a mean. We then calculated the difference between the caged predator mean and the no predator mean (NCEs of predators only), and the difference between the uncaged predator mean and the no predator mean (total predator effect). Dividing the NCEs by total predator effects then gave us the relative size of the NCEs (as a percentage of total predator effects). To generate a distribution, this method was repeated 10,000 times for each parameter. As randomized bootstraps generate a distribution of differences between treatment means, confidence limits around the estimate can be reported (Forbes and Hammill, 2013). In several instances the difference between no predator treatments and caged predator treatments was greater than the difference between no predator and uncaged predator treatments, resulting in the median reported size of NCEs being greater than $100 \%$ of total predator effects. However for all response variables the lower $95 \%$ confidence limit was $<100 \%$, demonstrating that NCEs were not significantly greater than total predator effects, and values $>100 \%$ are likely statistical artefacts.

\section{Results}

Macro-invertebrate community composition differed significantly among no predator, caged predator, and uncaged predator treatments $\left(f_{(2,27)}=14.1, \mathrm{p}<0.001\right.$, PERMANOVA, Figure

2). Pair-wise comparisons showed that community composition in control treatments differed 
1 from caged predator treatments $\left(f_{(1,18)}=29.4\right.$, adjusted $\mathrm{p}=0.003$, PERMANOVA, Figure 2)

2 and uncaged predator treatments $\left(f_{(1,18)}=20.6\right.$, adjusted $\mathrm{p}=0.003$, PERMANOVA, Figure 2).

3 Caged and uncaged predator treatments also differed from each other $\left(f_{(1,18)}=5.6\right.$ adjusted $\mathrm{p}$ $4=0.006$, PERMANOVA, Figure 2).

To understand how macro-invertebrate communities differed between treatments, we quantified how densities within taxonomic groups differed among control, caged predator and uncaged predator treatments. Compared to no-predator controls, densities of all mosquito genera were reduced by $77.4 \%(95 \% \mathrm{CI}=70.8 \%-83.0 \%)$ in the presence of caged predators (Table 1, Figure 3a), and 91.7\% (88.4\%-94.7\%) when predators were uncaged (Table 1, Figure 3a). Densities of Culex and Wyeomyia were significantly lower in uncaged compared to caged predator treatments, while Anopheles densities were not different between caged and uncaged treatments (Table 1, Figure 3a). For all mosquito species, more than $50 \%$ of the total predator effect on densities was due to NCEs (Figure 4).

Macro-invertebrate detritivores were reduced by both caged predators and uncaged predators same degree $[93.7 \%(87.9 \%-97.0 \%)$ and $88.9 \%(76.4 \%-95.2 \%)$ respectively, (Table 1, Figure 3b-d)]. Therefore, NCEs appeared to account for the vast majority $(\sim 100 \%)$ of the total predator effects on detritivore densities (Figure 4).

Effects of predators on mosquito and detritivore densities appeared to differentially alter densities of the microbial community (Table 1, Figure 3e). Compared to bromeliads without predators, Ciliophora densities were increased by $1010.9 \%$ (645.9\%-1732.3\%) presence of uncaged predators, but showed no significant density changes with caged predators. Mastigophora densities were 266.4\% (103.4\% - 574.3\%) higher in the presence of caged predators, and $1405.2 \%$ (539.4\% - 3218.5) higher when predators were uncaged (Table 1, Figure 3e). Rotifera densities were not affected by any experimental treatment (Table 1, 
1 Figure 3e). Predator NCEs accounted for the minority of total predator effects $(<50 \%)$ for all

2 micro-organism phyla (Figure 4).

3 Community respiration differed among predator treatments (Table 1, Figure 3f).

4 Compared to no predator controls, dissolved $\mathrm{CO}_{2}$ concentrations were increased by $123.1 \%$

$5 \quad(47.1 \%-299.2 \%)$ and $201.7 \%(95.2 \%-448.9 \%)$ in caged predator and uncaged predator

6 treatments respectively (Table 1, Figure 3f). The size of predator NCEs on $\mathrm{CO}_{2}$

7 concentrations was a relatively large $(61.4 \%)$ percentage of total predator effects $(34.8 \%$ -

$896.2 \%$, Figure 4).

9

\section{Discussion}

11 We have demonstrated that predator NCEs are strong enough to account for the majority of total predator effects on community composition, leading to altered food web structure and ecosystem processes in a natural bromeliad ecosystem. Within our experiment, the threat of predation alone substantially reduced macro-invertebrate densities, generating a trophic cascade that increased microbial densities. We believe that higher microbial densities led to an increase in overall community respiration, reported as increased $\mathrm{CO}_{2}$ concentrations. Our composition, and that NCE-mediated differences in community composition alter ecosystem respiration.

Our results showed that all macro-invertebrate species decreased in the presence of caged predators (NCEs only). This result provides clues as to the mechanisms by which predator NCEs affected prey densities. Predator NCEs may lead to community-level changes by altering competitive interactions among prey species. Following exposure to predation

24 risk, prey may induce defences that affect their ability to compete with other species, reducing some prey densities and increasing others (Mowles, Rundle \& Cotton, 2011). 
1 However, our data do not support this as all macro-invertebrate species decreased in the

2 presence of caged predators, suggesting no species gained an advantage over its competitors

3 as a result of predation risk. In lieu of NCE-mediated effects on competition, NCEs could

4 have reduced macro-invertebrate densities through; i) changes in adult oviposition behaviour,

5 affecting how larval communities were assembled, and/or ii) changes in larval development

6 rate, increasing the rate at which individuals left the community through emergence. Many

7 insect species have the ability to detect the presence of predators in an ecosystem and choose

8 to oviposit elsewhere (Brodin et al., 2006; Vonesh and Blaustein, 2010), reducing the number

9 of colonists. Diptera species have also been shown to increase larval development rates in

10 response to the threat of predation (Hammill and Beckerman, 2010), which would reduce

11 densities within the community through faster emergence rates. Although the most parsimonious explanation for predator NCEs on larval macro-invertebrate densities is reduced oviposition rates and/or increased development rates, we cannot discount the possibility that predator NCEs also operate via indirect means. In pitcher plants, larval mosquito growth is facilitated by detritivores breaking down detritus (Heard 1994), but it is unknown if similar effects occur in bromeliads. If so, negative effects of NCEs on detritivore oviposition rates could have reduced facilitative effects of detritivores on larval mosquitoes. The threat of predation alone was sufficient to cause an increase in the density of protists, presumably related to the decrease in densities of their predators (mosquito larvae).

20 Increases in protist densities following a decrease in mosquito abundance are well-

21 documented in aquatic systems (Eisenberg et al., 2000; Kneitel and Miller, 2002). It is

22 unlikely that protist densities were directly affected by predator NCEs or the release of 23 nutrients from predators in caged or uncaged treatments, as previous experiments have shown 24 no effect of free roaming odonates on protozoan (ciliates, flagellates) or rotifer densities in 25 the absence of mosquitoes (Srivastava and Bell, 2009). 
2 NCEs was large, $>50 \%$ for all mosquito species and $~ 100 \%$ for Anopheles mosquitoes and

3 macro-invertebrate detritivores. Predatory M. modesta are voracious, generalist predators,

4 able to consume all other bromeliad-dwelling macro-invertebrates (Srivastava et al., 2005),

5 meaning all macro-invertebrates should be under some selection pressure to avoid them.

6 However, we postulate that differences in the contribution of NCEs between prey are related

7 to the life-histories of the species involved. For example, within the mosquito community, the

8 contribution of predator NCEs to total predator effects was greatest for Anopheles. Unlike

9 Culex and Wyeomyia larvae, Anopheles lack a breathing siphon and are therefore constrained

10 to the water surface, meaning when viewed from underneath they are silhouetted and easily

11 detected by M. modesta. This ease of detection by predators may mean Anopheles experience

12 a relatively higher pressure to avoid ovipositing in predator locations. However, obtaining a

13 full understanding of the mechanisms leading to interspecific differences in the magnitude of

14 predator NCEs would require further, species-specific investigations.

The risk of odonate predation also affected community respiration, as measured by

16 concentrations of dissolved $\mathrm{CO}_{2}$ in the water. Community respiration increased in the

17 presence of both caged and uncaged predatory odonates, even though these bromeliads

18 contained fewer macro-invertebrates. A probable explanation for higher $\mathrm{CO}_{2}$ concentrations

19 in predator treatments was the increase in protist densities. Despite their negative effects on

20 bacterial abundance, bacterivorous protists have been shown to increase detrital

21 decomposition, likely due to increased levels of bacterial turnover (Ribblett et al., 2005).

22 Furthermore rates of decomposition are correlated with rates of community respiration

23 (Young et al., 2008), suggesting that higher protist densities would lead to greater

24 remineralization of organic matter to $\mathrm{CO}_{2}$. It is unlikely that the presence of predators

25 themselves was enough to increase $\mathrm{CO}_{2}$ concentrations, as the single damselfly larvae present 
1 in each predator treatment would have generated $<1 \%$ of the total $\mathrm{CO}_{2}$ generated by protist

2 and rotifer respiration (calculation in Appendix 1). Furthermore, a previous study showed

3 that in a bromeliad food chain containing odonates and detritivorous macro-invertebrates, $M$.

4 modesta reduced decomposition rates and $\mathrm{CO}_{2}$ concentrations (Atwood et al. 2014), the

5 opposite of predator effects on $\mathrm{CO}_{2}$ in the present study. One difference between the current

6 study and Atwood et al. (2014) is that the current study included mosquitoes, which led to

7 additional trophic levels in the food web. Due to omnivory amongst protists, determining the

8 number of trophic levels and the dominant pathways by which predators increased $\mathrm{CO}_{2}$

9 concentrations becomes difficult. Yet, the fact that in the current study predators increased

$10 \mathrm{CO}_{2}$ concentrations suggests the mosquito-microbial component of the food web dominates

11 ecosystem respiration, rather than the macro-invertebrate detritivore component exclusively

12 used in previous studies (Atwood et al., 2014).

13 In many complex natural systems, predator NCEs may be overlooked due to

14 difficulties associated with the quantification of their relative contribution. However, we

15 show that failing to quantify and account for NCEs may lead to misunderstandings of the

16 mechanisms by which predators affect community assembly, food web structure and

17 ecosystem function. The current study shows that NCEs are the dominant mechanism by

18 which predators influence community composition and functioning of bromeliad ecosystems.

19 As global predator densities are in serious decline (Ripple et al., 2014), management

20 strategies designed to replace predators ecologically must account for both consumptive and

21 non-consumptive predator effects. Failing to account for predator NCEs may have serious

22 implications for the structure of natural communities, and the ecological functions they

23 perform. 
1 Acknowledgments Permission to work in the Área de Conservación Guanacaste (ACG) was

2 obtained from MINAE, the Costa Rican ministry for environment and energy. Particular

3 thanks to Róger Blanco for assistance with administration and logistics. This work was

4 funded through an NSERC E.W.R. Steacie Memorial Fellowship awarded to D.S.S. We

5 thank Calixto Moraga and Petrona Rios for invaluable help in the field. We would like to also

6 thank Oswald J. Schmitz, Wolf Mooij and two anonymous reviewers for their insightful

7 comments on earlier versions of this manuscript. 


\section{$1 \quad$ References}

2 Atwood T, Hammill E, Srivastava D, Richardson J. 2014. Competitive displacement alters

3 top-down effects on carbon dioxide concentrations in a freshwater ecosystem. Oecologia 75:

$4 \quad 353-361$.

5 Atwood TB, Hammill E, Grieg H, Kratina P, Shurin JB, Srivastava DS, Richardson JS. 2013.

6 Predator-induced reduction of freshwater carbon dioxide emissions. Nature Geoscience 6:

$7 \quad 191-194$.

8 Berendonk TU, Bonsall MB. 2002. The phantom midge and a comparison of metapopulation

9 structures. Ecology 83: 116-128.

10 Borg I, Groenen P. 2005. Modern multidimensional scaling: Theory and applications. New

11 York: Springer-Verlag.

12 Brodin T, Johansson F, Bergsten J. 2006. Predator related oviposition site selection of aquatic

13 beetles (Hydroporus spp.) and effects on offspring life-history. Freshwater Biology 51: 1277-

141285.

15 Cadotte MW, Carscadden K, Mirotchnick N. 2011. Beyond species: functional diversity and

16 the maintenance of ecological processes and services. Journal of Applied Ecology 48: 1079-

171087.

18 Carpenter SR. 1996. Microcosm experiments have limited relevance for community and

19 ecosystem ecology. Ecology 77: 677-680.

20 Cole JJ, Prairie YT, Caraco NF, McDowell WH, Tranvik LJ, Striegl RG, Duarte CM,

21 Kortelainen P, Downing JA, Middelburg JJ, Melack J. 2007. Plumbing the global carbon

22 cycle: Integrating inland waters into the terrestrial carbon budget. Ecosystems 10: 171-184.

23 Del Giorgio PA, Cole JJ, Caraco NF, Peters RH. 1999. Linking planktonic biomass and

24 metabolism to net gas fluxes in northern temperate lakes. Ecology 80: 1422-1431. 
1 Eisenberg JNS, Washburn JO, Schreiber SJ. 2000. Generalist feeding behaviors of Aedes

2 sierrensis larvae and their effects on protozoan populations. Ecology 81: 921-935.

3 Forbes C, Hammill E. 2013. Fear in the dark? Community-level effects of non-lethal

4 predators change with light regime. Oikos 122: 1662-1668.

5 Garpe KC, Yahya SAS, Lindahl U, Ohman MC. 2006. Long-term effects of the 1998 coral

6 bleaching event on reef fish assemblages. Marine Ecology Progress Series 315: 237-247.

7 Glazier DS. 2009. Metabolic level and size scaling of rates of respiration and growth in

8 unicellular organisms. Functional Ecology 23: 963-968.

9 Goffredi SK, Jang GE, Woodside WT, Ussler W. 2011. Bromeliad catchments as habitats for 10 methanogenesis in tropical rainforest canopies. Frontiers in Microbiology 2: 256.

11 Hammill E, Atwood TB, Corvalan P, Srivastava DS. 2015. Behavioural responses to

12 predation may explain shifts in community structure. Freshwater Biology 60: 125-135.

13 Hammill E, Beckerman AP. 2010. Reciprocity in predator-prey interactions: exposure to

14 defended prey and predation risk affects intermediate predator life history and morphology.

15 Oecologia 163: 193-202.

16 Hill JM, Weissburg MJ. 2013. Predator biomass determines the magnitude of non-

17 consumptive effects (NCEs) in both laboratory and field environments. Oecologia 172: 79-

1891.

19 Holm S. 1979. A simple sequentially rejective multiple test procedure. Scandinavian Journal 20 of Statistics 6: 65-70.

21 Hooper DU, Adair EC, Cardinale BJ, Byrnes JEK, Hungate BA, Matulich KL, Gonzalez A, 22 Duffy JE, Gamfeldt L, O'Connor MI. 2012. A global synthesis reveals biodiversity loss as a 23 major driver of ecosystem change. Nature 486: 105-U129.

24 Hope D, Dawson JJC, Cresser MS, Billett MF. 1995. A method for measuring free $\mathrm{CO}_{2}$ in 25 upland streamwater using headspace analysis. Journal of Hydrology 166: 1-14. 
1 Kneitel JM, Miller TE. 2002. Resource and top-predator regulation in the pitcher plant

2 (Sarracenia purpurea) inquiline community. Ecology 83: 680-688.

3 Kraus JM, Vonesh JR. 2010. Feedbacks between community assembly and habitat selection

4 shape variation in local colonization. Journal of Animal Ecology 79: 795-802.

5 Lawton JH. 1971. Ecological energetics studies on larvae of damselfly Pyrrhosoma

6 nymphula (sulzer) (Odonata-Zygoptera). Journal of Animal Ecology 40: 385-423.

7 Martinson GO, Werner FA, Scherber C, Conrad R, Corre MD, Flessa H, Wolf K, Klose M,

8 Gradstein SR, Veldkamp E. 2010. Methane emissions from tank bromeliads in neotropical

9 forests. Nature Geoscience 3: 766-769.

10 Ngai JT, Srivastava DS. 2006. Predators accelerate nutrient cycling in a bromeliad

11 ecosystem. Science 314: 963-963.

12 Oksanen J, Blanchet FG, Kindt R, Legendre P, Minchin PR, O'Hara RB, Simpson GL,

13 Solymos P, Henry M, Stevens H, Wagner H. 2012. vegan: Community Ecology Package. R 14 package version 2.0-3.

15 Peacor SD, Pangle KL, Schiesari L, Werner EE. 2012. Scaling-up anti-predator phenotypic 16 responses of prey: impacts over multiple generations in a complex aquatic community.

17 Proceedings of the Royal Society B-Biological Sciences 279: 122-128.

18 Peacor SD, Werner EE. 2001. The contribution of trait-mediated indirect effects to the net 19 effects of a predator. Proceedings of the National Academy of Sciences of the United States 20 of America 98: 3904-3908.

21 Preisser EL, Orrock JL, Schmitz OJ. 2007. Predator hunting mode and habitat domain alter 22 nonconsumptive effects in predator-prey interactions. Ecology 88: 2744-2751.

23 R Development Core Team. 2013. R: A language and environment for statistical computing. 24 Computing RFfS editor. Vienna. 
1 Resetarits WJ, Jr., Binckley CA. 2009. Spatial contagion of predation risk affects

2 colonization dynamics in experimental aquatic landscapes. Ecology 90: 869-876.

3 Ribblett SG, Palmer MA, Coats DW. 2005. The importance of bacterivorous protists in the

4 decomposition of stream leaf litter. Freshwater Biology 50: 516-526.

5 Ripple WJ, Estes JA, Beschta RL, Wilmers CC, Ritchie EG, Hebblewhite M, Berger J,

6 Elmhagen B, Letnic M, Nelson MP, Schmitz OJ, Smith DW, Wallach AD, Wirsing AJ. 2014.

7 Status and ecological effects of the world's largest carnivores. Science 343: 151.

8 Schindler DE, Carpenter SR, Cole JJ, Kitchell JF, Pace ML. 1997. Influence of food web

9 structure on carbon exchange between lakes and the atmosphere. Science 277: 248-251.

10 Schmitz OJ, Beckerman AP, Obrien KM. 1997. Behaviorally mediated trophic cascades:

11 Effects of predation risk on food web interactions. Ecology 78: 1388-1399.

12 Schulze E-D, Mooney HA. 1994. Biodiversity and ecosystem function: with 22 tables:

13 Springer.

14 Srivastava DS. 2006. Habitat structure, trophic structure and ecosystem function: interactive

15 effects in a bromeliad-insect community. Oecologia 149: 493-504.

16 Srivastava DS, Bell T. 2009. Reducing horizontal and vertical diversity in a foodweb triggers

17 extinctions and impacts functions. Ecology Letters 12: 1016-1028.

18 Srivastava DS, Kolasa J, Bengtsson J, Gonzalez A, Lawler SP, Miller TE, Munguia P,

19 Romanuk T, Schneider DC, Trzcinski MK. 2004. Are natural microcosms useful model

20 systems for ecology? Trends in Ecology \& Evolution 19: 379-384.

21 Srivastava DS, Melnychuk MC, Ngai JT. 2005. Landscape variation in the larval density of a

22 bromeliad-dwelling zygopteran, Mecistogaster modesta (Odonata: Pseudostigmatidae).

23 International Journal of Odonatology 8: 67-79. 
1 Srivastava DS, Trzcinski MK, Richardson BA, Gilbert B. 2008. Why are predators more

2 sensitive to habitat size than their prey? insights from bromeliad insect food webs. American

3 Naturalist 172: 761-771.

4 Strickland MS, Hawlena D, Reese A, Bradford MA, Schmitz OJ. 2013. Trophic cascade

5 alters ecosystem carbon exchange. Proceedings of the National Academy of Sciences of the

$6 \quad$ United States of America 110: 11035-11038.

7 Tollrian R, Harvell CD. 1999. The Ecology and Evolution of Inducible Defenses. Princeton:

8 Princeton University Press.

9 Trussell GC, Ewanchuk PJ, Matassa CM. 2006a. The fear of being eaten reduces energy

10 transfer in a simple food chain. Ecology 87: 2979-2984.

11 Trussell GC, Ewanchuk PJ, Matassa CM. 2006b. Habitat effects on the relative importance of 12 trait- and density-mediated indirect interactions. Ecology Letters 9: 1245-1252.

13 Vonesh JR, Blaustein L. 2010. Predator-induced shifts in mosquito oviposition site selection:

14 a meta-analysis and implications for vector control. Israel Journal of Ecology \& Evolution 15 56: 263-279.

16 Vonesh JR, Kraus JM, Rosenberg JS, Chase JM. 2009. Predator effects on aquatic

17 community assembly: disentangling the roles of habitat selection and post-colonization

18 processes. Oikos 118: 1219-1229.

19 Werner EE, Anholt BR. 1996. Predator-induced behavioral indirect effects: Consequences to

20 competitive interactions in anuran larvae. Ecology 77: 157-169.

21 Young RG, Matthaei CD, Townsend CR. 2008. Organic matter breakdown and ecosystem 22 metabolism: functional indicators for assessing river ecosystem health. Journal of the North 23 American Benthological Society 27: 605-625. 


\section{Appendix 1. Contribution of damselfly larva to community respiration}

2 As the addition of a damselfly in the predator treatments may increase community

3 respiration, we estimated total microbial respiration and compare it to the respiration rates of

4 damselfly to help ascertain the major source of $\mathrm{CO}_{2}$. The micro-organisms we measured

5 ranged in size, with a volume of $\sim 3500 \mu \mathrm{m}^{3}$ being average. According to Galizer (Glazier,

6 2009) a single celled heterotroph of this size will have a metabolic rate $\left(\mathrm{nL} \mathrm{O}_{2}\right.$ cell $\left.^{-1} \mathrm{~h}^{-1}\right)$ of

7 0.01. In the caged predator treatment containing the lowest micro-organismal densities, the

8 total bromeliad contained $\sim 450,000,000$ protists, meaning the total respiration per hour

9 attributable to the micro-organisms was $450000000 * 0.01=4500000 \mathrm{~nL} \mathrm{O}_{2}$ cell $^{-1} \mathrm{~h}^{-1}$, or

$10450 \mu \mathrm{L}$ per hour. Damselfly larvae respire at a rate of between 0.2 and $3.0 \mu \mathrm{L}$ per hour

11 (Lawton, 1971), suggesting that even at their highest respiration rates the single caged damselfly would maximally contribute less than $1 \%$ of the $\mathrm{CO}_{2}$ that is attributable to microorganisms.

In addition to the above calculation, our conclusion that community respiration is attributable mainly to the microbial increase is justified on the basis of two previous studies. These previous investigations used the exact same system, but without the mosquito-microbe component of the food web (Atwood et al., 2013; Atwood et al., 2014). In both of these studies, predator presence reduced $\mathrm{CO}_{2}$ of three-tier bromeliad food webs. The difference in the results of the current investigation and these previous papers is attributed to differences in

20 food chain length. In the previous papers the authors study a simplified odd-numbered food 21 chain, while the current investigation looks at a more reticulate even-numbered food chain. If the increase in community respiration we observe in the present study were due mainly to the addition of predators, we would have expected to see an increase in community respiration

24 (and therefore $\mathrm{CO}_{2}$ ) in these earlier studies, when in fact we see the opposite. 


\section{Tables}

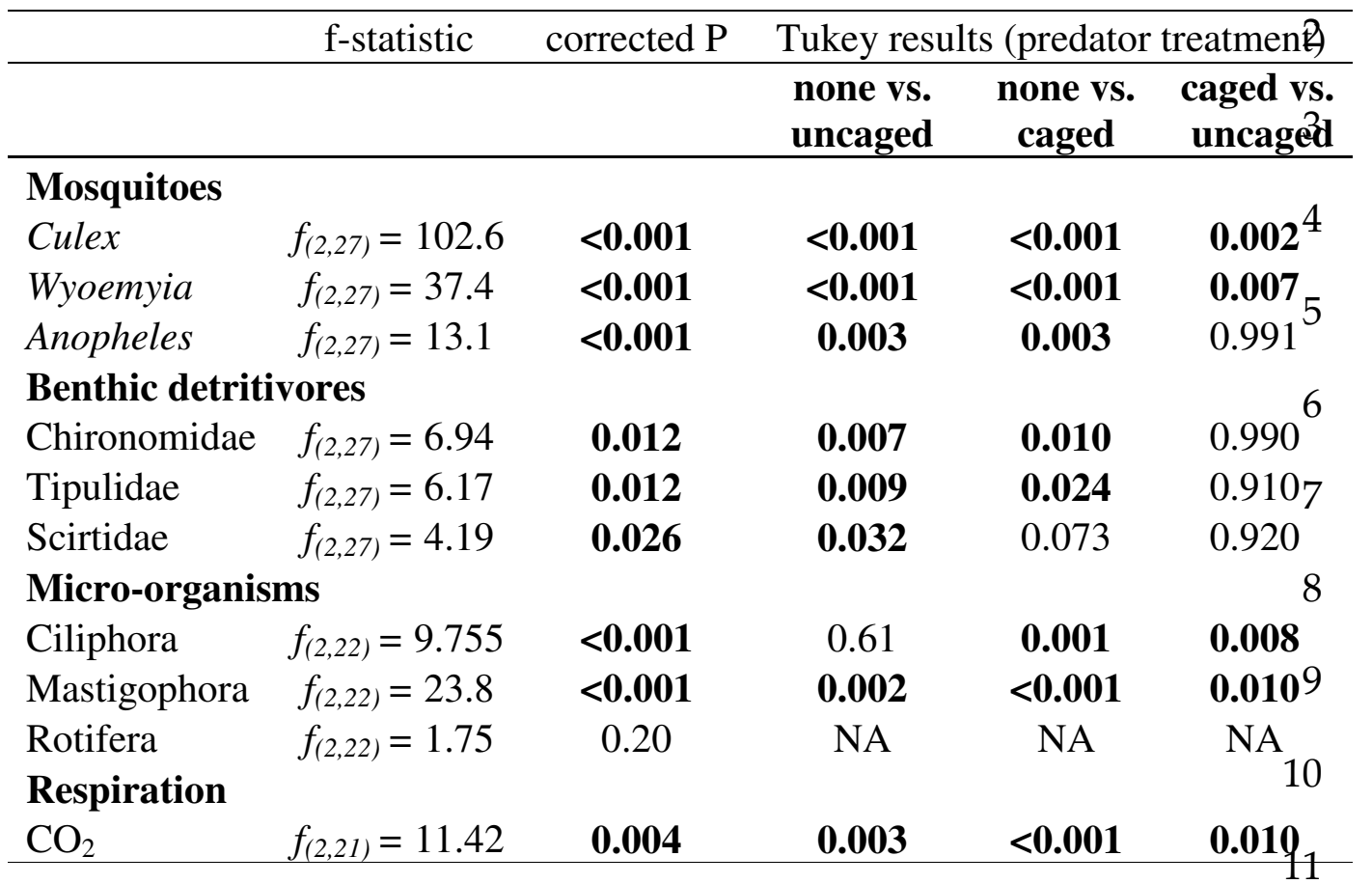

12 Table 1. Results from ANOVAs performed on all species and $\mathrm{CO}_{2}$ concentrations, with

13 Tukey tests where applicable. "Corrected P" denotes the P-value following Holm-Bonferroni

14 correction (Holm, 1979). Bolded values indicate significant differences at 0.05 level. 


\section{$1 \quad$ Figures}

(a)

(i)

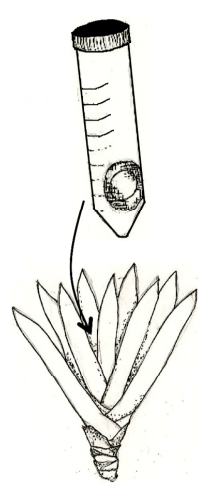

(ii)

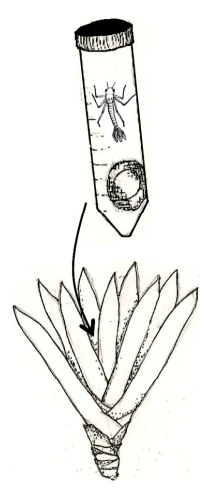

(b)

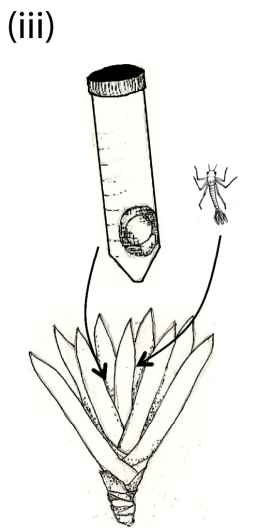

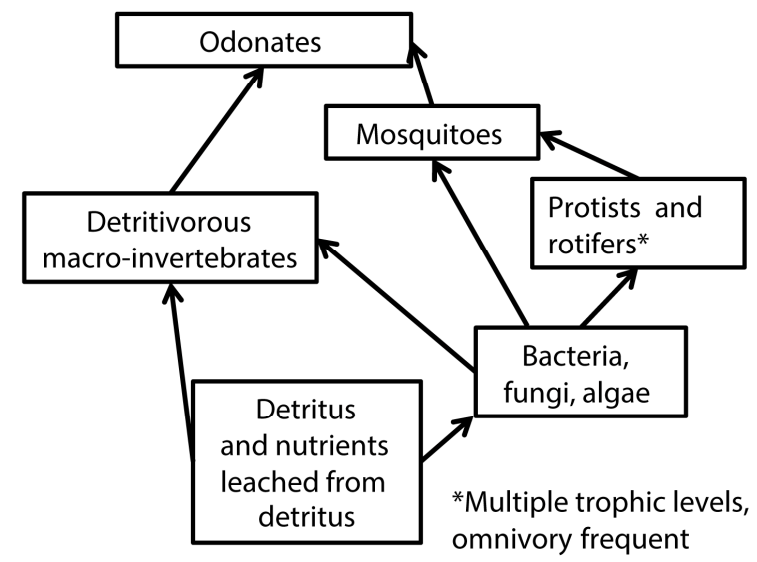

3

4 Figure 1. (a) Illustration of the structural nature of Guzmania bromeliads, and the technique

5 used to generate experimental treatments. Damselfly larvae and tubes are enlarged 4x relative

6 to bromeliads to improve clarity. (i) No predator treatments, (ii) Caged predator treatments,

7 non-consumptive effects (NCEs) only, (iii) Uncaged predator treatments, both consumptive

8 effects and NCEs. (b) Simplified bromeliad food web demonstrating proposed energy flow

9 between trophic groups.

10 


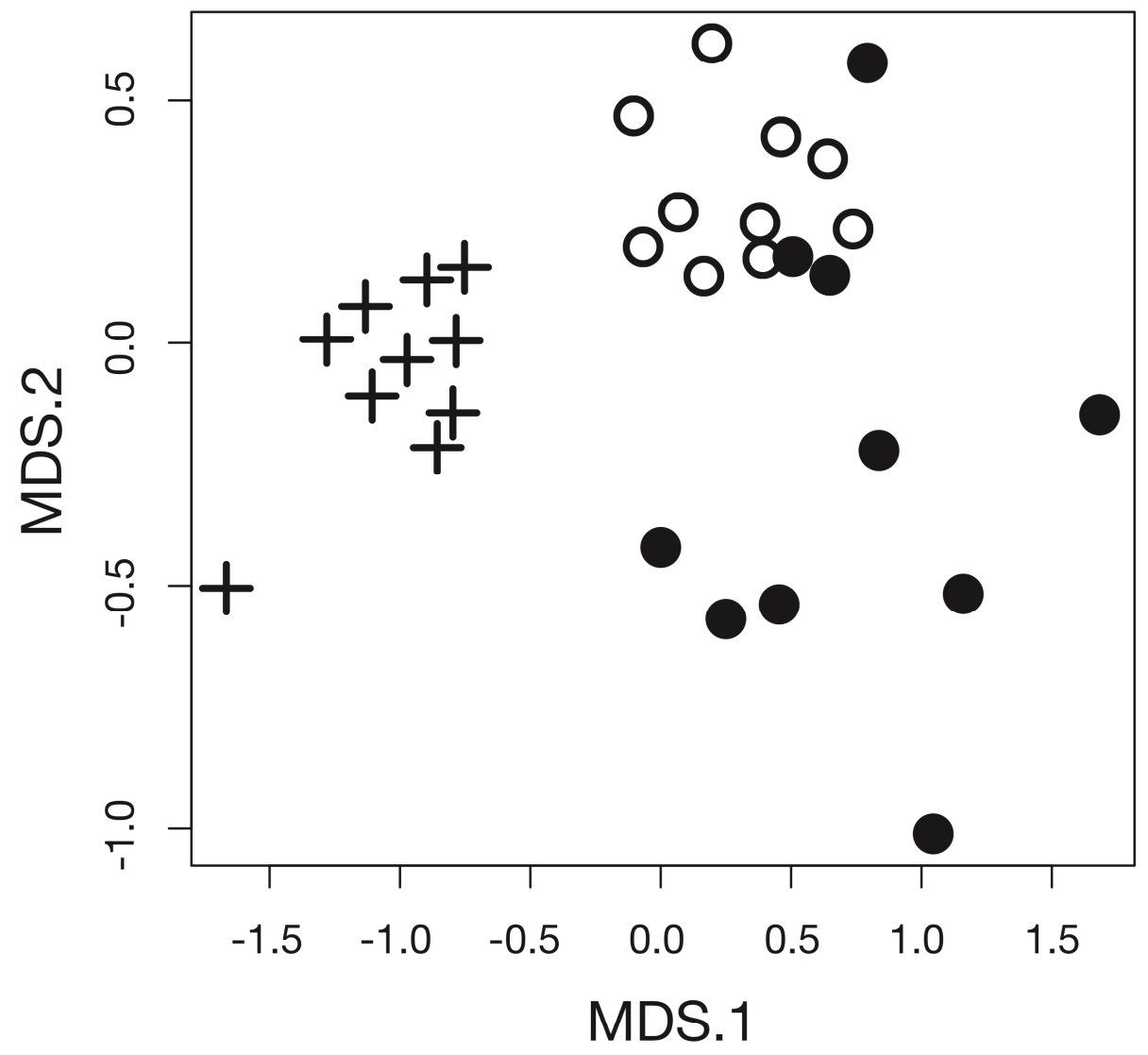

1

Figure 2. Multidimensional scaling plot (MDS) illustrating how predators alter the macro-

3 invertebrate community composition in bromeliads. Within the plot, each point represents a

4 single bromeliad community. Treatments containing predators are represented by circles,

5 either caged (NCEs) $\mathrm{O}$, or uncaged (total predator effects $\bigcirc$ ). No predator controls (no

6 predator effects) are represented by crosses $(+)$. The distance between points is proportional

7 to the similarity in community composition, meaning nearby points represent similar

8 communities.

9 
(a)

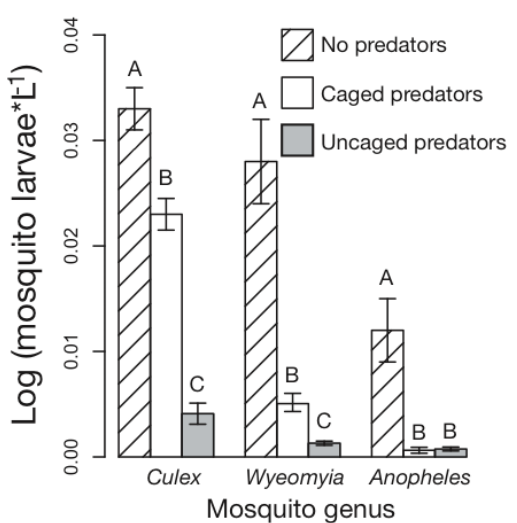

(c)

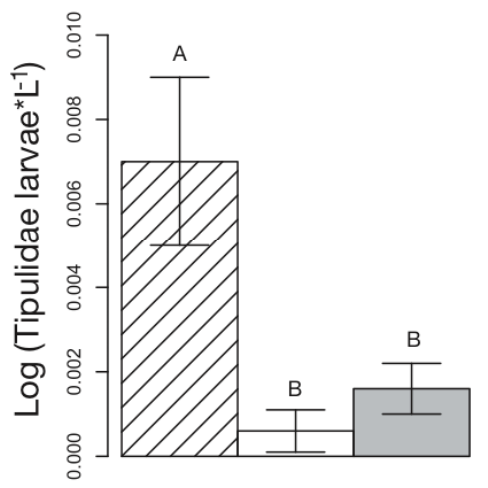

(e)

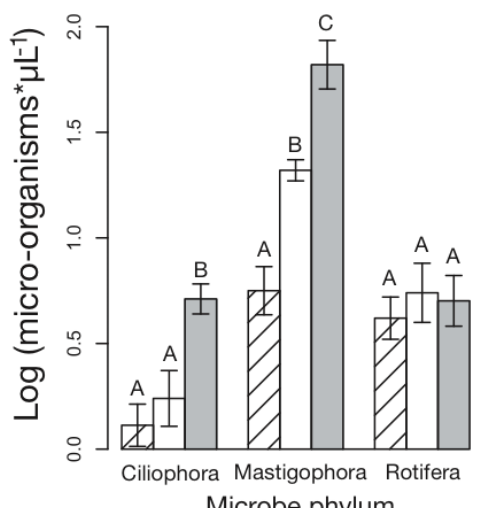

(b)

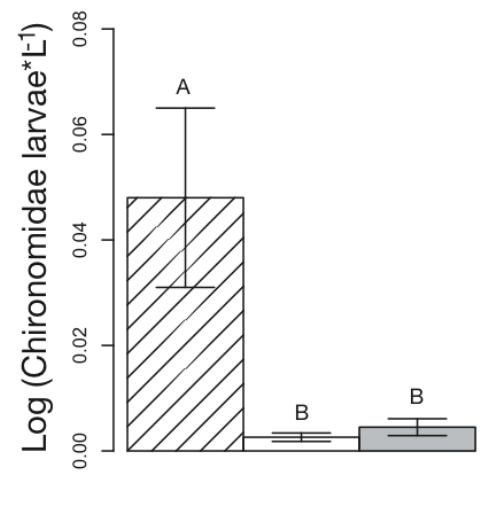

(d)

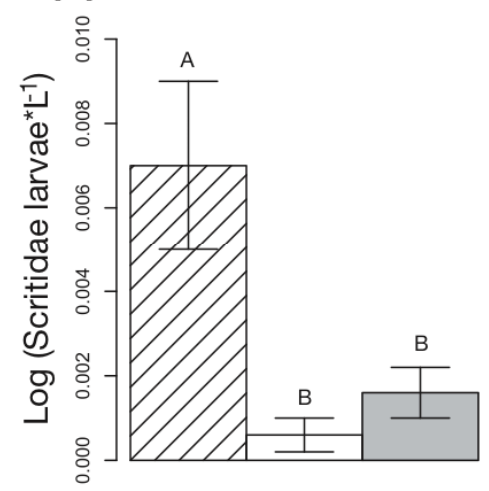

(f)

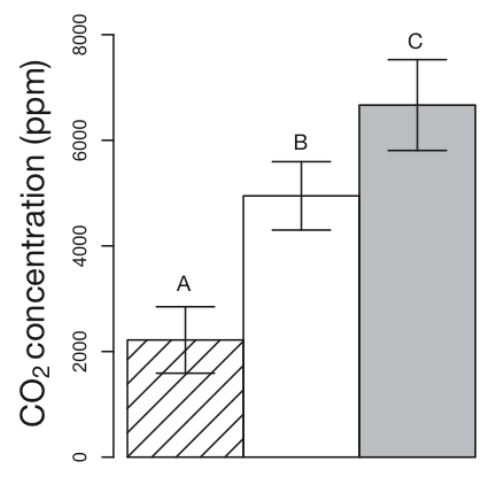

2 Figure 3. Predator effects on densities of (a), mosquitoes (filter-feeders) (b), Chironomidae

3 (c), Tipulidae, (d), Scirtidae, (e) and micro-organisms, and (f) in situ $\mathrm{CO}_{2}$ concentrations of

4 bromeliad ecosystems. Caged predator treatments were only exposed to the non-consumptive

5 effects of predators, while uncaged predator treatments were exposed to both the non-

6 consumptive and consumptive effects of predators. Different letters denote treatments that

7 differ significantly from each other according to post-hoc Tukeys testing within a genus (a),

8 family (b-d), or phyla (f). Bars represent means \pm standard errors. 


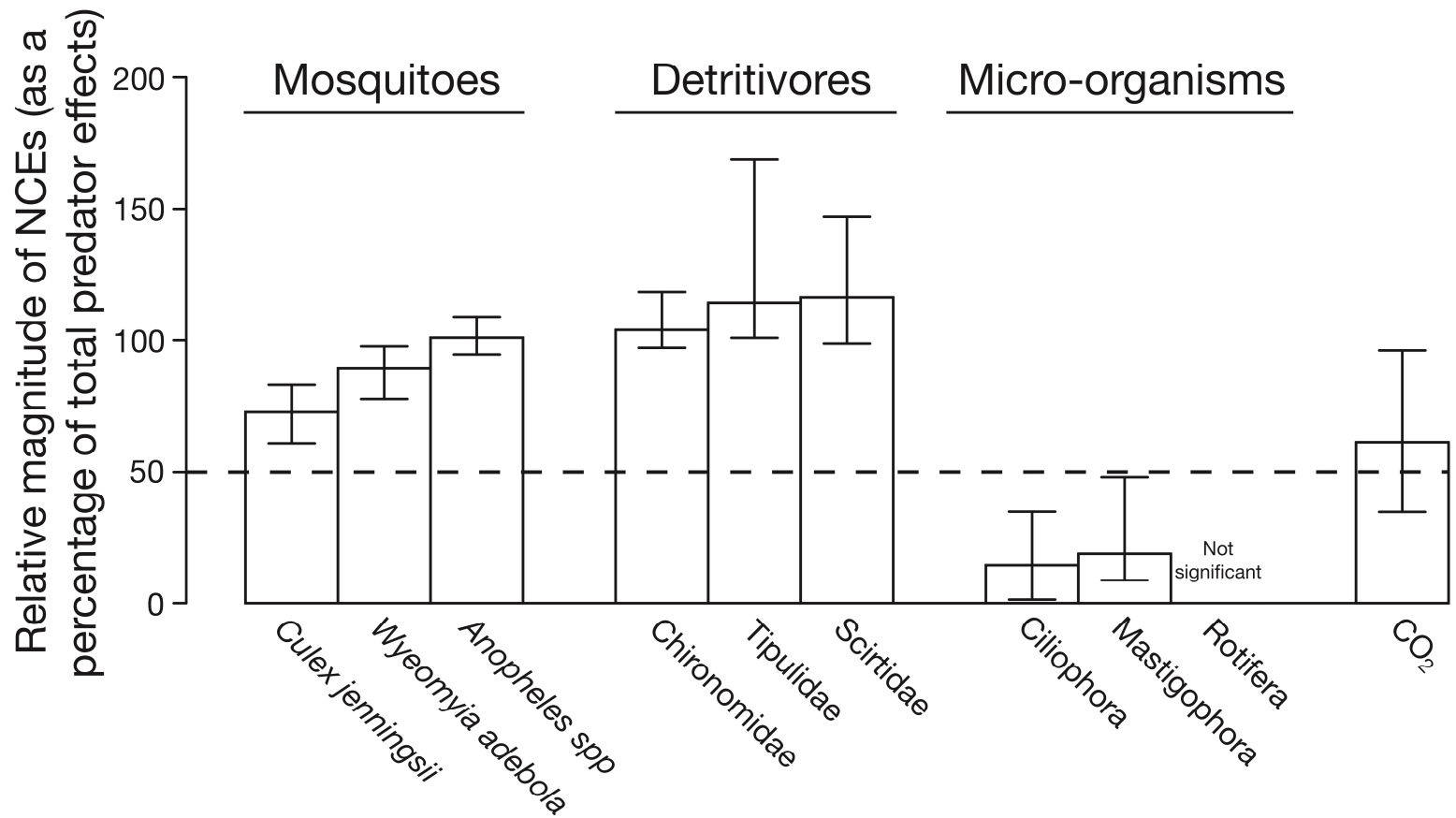

2 Figure 4. Relative magnitude of non-consumptive effects (NCEs), compared to total predator

3 effects, on species and families of organisms, as well as $\mathrm{CO}_{2}$ concentrations, within

4 bromeliad communities. For parameters where the bar height is greater than $100 \%$ the

5 difference between caged predator and no predator treatments was greater than the difference

6 between uncaged predator and no predator treatments. Data are means $\pm 95 \%$ confidence

7 limits. 


\section{Supplementary material}

\section{Appendix 1. Contribution of damselfly larva to community respiration}

4 As the addition of a damselfly in the predator treatments may increase community

5 respiration, we estimated total microbial microbial respiration and compare it to the

6 respiration rates of damselfly to help ascertain the major source of $\mathrm{CO}_{2}$. The micro-

7 organisms we measured ranged in size, with a volume of $\sim 3500 \mu \mathrm{m}^{3}$ being average.

8 According to Galizer (Glazier 2009) a single celled heterotroph of this size will have

9 a metabolic rate $\left(\mathrm{nL} \mathrm{O} \mathrm{cell}^{-1} \mathrm{~h}^{-1}\right)$ of 0.01 . In the caged predator treatment containing

10 the lowest micro-organismal densities, the total bromeliad contained $\sim 450000000$

11 protists, meaning the total respiration per hour attributable to the micro-organisms was $450000000^{*} 0.01=4500000 \mathrm{~nL} \mathrm{O}_{2}$ cell- $^{-1} \mathrm{~h}^{-1}$, or $450 \mu \mathrm{L}$ per hour. Damselfly larvae

13 respire at a rate of between 0.2 and 3.0 $\mu \mathrm{L}$ per hour (Lawton 1971), suggesting that

14 even at their highest respiration rates the single caged damselfly we added to the

15 predator treatments would contribute less than $0.1 \%$ of the $\mathrm{CO}_{2}$ that is attributable to 16 micro-organisms.

In addition to the above calculation, our conclusion that community

respiration is attributable mainly to the microbial increase is justified on the basis of

19 two previous studies. These previous investigations used the exact same system, but

20 without the mosquito-microbe component of the food web (Atwood et al. 2013,

21 Atwood et al. 2014). In both of these studies, predator presence reduced $\mathrm{CO}_{2}$ of

22 three-tier bromeliad food webs. The difference in the results of the current 
1 investigation and these previous papers is attributed to differences in food chain

2 length. In the previous papers the authors study a simplified odd-numbered food

3 chain, while the current investigation looks at a more reticulate even-numbered food

4 chain. If the increase in community respiration we observe in the present study were

5 due mainly to the addition of predators, we would have expected to see an increase

6 in community respiration (and therefore $\mathrm{CO}_{2}$ ) in these earlier studies, when in fact

7 we see the opposite.

9 Appendix 2. Calculation of the potential for macroinvertebrates offered as food to

10 act as a nutrient subsidy.

11 The possibility exists that increased $\mathrm{CO}_{2}$ concentrations in the caged predator

12 treatments (NCEs alone) may have been due to nutrient subsidies offered to the

13 predator as food. To estimate the importance of the carbon added as food, we

14 calculated the total mass of carbon added as food, and compared this value to the amount of carbon added to all bromeliads as leaf litter.

Leaf litter from tropical forests is composed of $\sim 47 \%$ carbon (Martin and

17 Thomas 2011). In each bromeliad, we added 200mg (dry weight) leaf litter per 100ml

18 plant volume. The mean volume across plants was $1013.5 \mathrm{ml}$, meaning we added

$192027 \mathrm{mg}$ dry weight leaf litter, which equates to 952.7mg C. We added a total of 30

20 food items (mosquito and chironomid larvae) to each of the caged treatments over

21 the course of the experiment. These food items were all $\sim 5 \mathrm{~mm}$ total length, we

22 therefore used the length of $5 \mathrm{~mm}$ to calculate dry mass using length-weight 
1 regression values for aquatic insects (Sabo et al. 2002). Using these values, we

2 calculate we added a maximum of $98.6 \mathrm{mg}$ of food, which equates to $44.37 \mathrm{mg} \mathrm{C}$

3 according to estimates of the carbon composition of aquatic insects (Kraus and

4 Vonesh 2012). This therefore means that the amount of carbon we introduced as

5 food in the caged treatments was $<5 \%$ of what was initially introduced as leaf litter.

6 This value of $5 \%$ is around $1 / 10^{\text {th }}$ of the size of the error bars around the $\mathrm{CO}_{2}$ estimate

7 in figure 4 , suggesting that the contribution to $\mathrm{CO}_{2}$ concentrations made by the

8 addition of food items has not substantially affected the results. This value of $5 \%$

9 would also be an over-estimate as it does not include carbon introduced to all

10 replicates as leaf litter falling naturally from the trees during the experiment. For

11 these reasons we believe that although adding food items to the caged predator

12 treatments may have slightly increased $\mathrm{CO}_{2}$ concentrations, the observed difference

13 in $\mathrm{CO}_{2}$ concentrations between our no predator and caged predator treatments is

14 primarily due to changes in community composition, rather than the introduction of

15 food items.

17 References for Supplementary material

18 Atwood, T., E. Hammill, D. Srivastava, and J. Richardson. 2014. Competitive

19 displacement alters top-down effects on carbon dioxide concentrations in a

20 freshwater ecosystem. Oecologia 75:353-361. 
1 Atwood, T. B., E. Hammill, H. Grieg, P. Kratina, J. B. Shurin, D. S. Srivastava, and J. S. Richardson. 2013. Predator-induced reduction of freshwater carbon dioxide emissions. Nature Geoscience 6:191-194.

4 Glazier, D. S. 2009. Metabolic level and size scaling of rates of respiration and growth in unicellular organisms. Functional Ecology 23:963-968.

6 Kraus, J. M., and J. R. Vonesh. 2012. Fluxes of terrestrial and aquatic carbon by emergent mosquitoes: a test of controls and implications for cross-ecosystem linkages. Oecologia 170:1111-1122.

9 Lawton, J. H. 1971. Ecological energetics studies on larvae of damselfly Pyrrhosoma nymphula (sulzer) (Odonata-Zygoptera). Journal of Animal Ecology 40:385423.

Martin, A. R., and S. C. Thomas. 2011. A reassessment of carbon content in tropical trees. Plos One 6:e23533.

14 Sabo, J. L., J. L. Bastow, and M. E. Power. 2002. Length-mass relationships for adult aquatic and terrestrial invertebrates in a California watershed. Journal of the North American Benthological Society 21:336-343. 